\title{
Situação epidemiológica da brucelose bovina no Estado de Rondônia
}

\author{
[Epidemiological situation of bovine brucellosis in the State of Rondônia, Brazil] \\ K.S. Villar ${ }^{1}$, M. Amaku ${ }^{1}$, R.A. Dias ${ }^{1}$, J.S. Ferreira Neto ${ }^{1}$, F. Benitez ${ }^{2}$, V.S.P. Gonçalves ${ }^{3}$, \\ V.C.F. Figueiredo ${ }^{4}$, J.R. Lôbo ${ }^{4}$, F. Ferreira ${ }^{1 *}$ \\ ${ }^{1}$ Faculdade de Medicina Veterinária e Zootecnia - USP \\ Av. Prof. Dr. Orlando Marques de Paiva, 87 \\ 05508-270 - São Paulo, SP \\ ${ }^{2}$ Secretaria de Agricultura e Abastecimento do Estado de Rondônia - Porto Velho, RO \\ ${ }^{3}$ Faculdade de Agronomia e Medicina Veterinária - UnB - Brasília, DF \\ ${ }^{4}$ Departamento de Saúde Animal - SDA-MAPA - Brasília, DF
}

\begin{abstract}
RESUMO
Realizou-se um estudo para caracterizar a situação epidemiológica da doença no Estado de Rondônia. O Estado foi estratificado em três circuitos produtores. Em cada circuito produtor foram amostradas aleatoriamente cerca de 300 propriedades e, dentro dessas, foi escolhido, de forma aleatória, um número pré-estabelecido de animais, dos quais foi obtida uma amostra de sangue. No total, foram amostrados 9.717 animais, provenientes de 927 propriedades. Em cada propriedade amostrada foi aplicado um questionário epidemiológico para verificar o tipo de exploração e as práticas zootécnicas e sanitárias que poderiam estar associadas ao risco de infecção pela doença. O protocolo de testes utilizado foi o da triagem com o teste do antígeno acidificado tamponado e o reteste dos positivos com o teste do 2mercaptoetanol. O rebanho foi considerado positivo, se pelo menos um animal foi reagente às duas provas sorológicas. As prevalências de focos e de animais infectados do Estado foram de 35,2\% [32,1$38,4 \%]$ e $6,2 \%[4,9-7,6 \%]$, respectivamente. Os resultados para os circuitos pecuários foram: circuito 1 , $41,9 \%$ [36,3-47,6\%] e $8,3 \%$ [5,9-10,8\%]; circuito $2,31,7 \%$ [26,5-37,2\%] e 5,9\% [4,3-7,6\%]; circuito 3 , $31,9 \%[26,7-37,4 \%]$ e $4,6 \%$ [2,5-6,6\%]. Os fatores de risco (odds ratio, OR) associados à condição de foco foram: histórico de aborto $(\mathrm{OR}=1,42[1,04-1,95])$ e exploração de corte $(\mathrm{OR}=1,75[1,30-2,38])$.
\end{abstract}

Palavras-chave: bovino, brucelose, prevalência, fatores de risco, Rondônia

\begin{abstract}
A study to characterize the brucellosis epidemiological situation in the State of Rondônia was carried out. The State was divided into three regions. Three hundred herds were randomly sampled in each region. A pre-established number of animals were sampled in each of these herds. From 927 herds and 9,717 serum samples were collected. In each herd, it was applied an epidemiological questionnaire regarding herd features and also husbandry and sanitary practices that could be associated with risk of infection. The serum samples were screened for antibodies to Brucella spp. by the Rose-Bengal Test (RBT), and all RBT-positive sera were re-tested by the 2-mercaptoethanol test (2-ME). The herd was considered positive if at least one animal was positive on both RBT and 2-ME tests. The prevalences of infected herds and animals in Rondônia State were 35.2\% [32.1-38.4\%] and 6.2\% [4.9-7.6\%], respectively. In the regions, the prevalences of infected herds and animals were, respectively: region 1, 41.9\% [36.3-47.6\%] and 8.3\% [5.9-10.8\%]; region 2, 31.7\% [26.5-37.2\%] and 5.9\% [4.3-7.6\%]; and region 3, 31.9\% [26.7$37.4 \%]$ and $4.6 \%$ [2.5-6.6\%]. The risk factors (odds ratio, OR) associated with the presence of the infection were: recent history of abortion $(O R=1.42[1.04-1.95])$ and beef herd $(O R=1.75[1.30-2.38])$.
\end{abstract}

Keywords: cattle, brucellosis, prevalence, risk factors, Rondônia, Brazil

Recebido em 27 de março de 2009

Aceito em 23 de setembro de 2009

*Autor para correspondência (corresponding author)

E-mail: fernando@vps.fmvz.usp.br 


\section{INTRODUÇÃO}

O Estado de Rondônia, localizado na região Norte do Brasil, ocupa uma área geográfica de $237.576 \mathrm{~km}^{2}$. O Estado tem 52 municípios sendo Porto Velho sua capital. Nesta área vivem 1.534.594 pessoas, segundo estimativa de 2005 . Possui 11.349.452 bovinos e 6.457 bubalinos, distribuídos em 49.600 propriedades aproximadamente (IBGE, 2007). A bovinocultura é a atividade de maior representatividade.

Os estados brasileiros da região norte têm importantes peculiaridades devido às condições ambientais, à presença da Floresta Amazônica, de áreas de preservação, de reservas indígenas e de sua localização distante da costa leste, onde se desenvolveram os principais pólos econômicos do País.

Historicamente, nas décadas de 1950 e 1960, existia na região amazônica uma estagnação econômica resultante do fim do ciclo da borracha. Associado a esse quadro, sempre houve a expectativa de integração da região à nação em conjunção com ameaças de internacionalização. Diante desse cenário, a ditadura militar criou a Zona Franca de Manaus com o objetivo de ocupar uma região despovoada. Assim, diferentemente de outras regiões do País, a atividade agropecuária foi implementada apenas recentemente na região norte e após o processo de industrialização.

Em virtude desse recente desenvolvimento, de modo mais expressivo, da atividade pecuária nos estados do norte e particularmente em Rondônia, não foram encontrados estudos epidemiológicos que permitam caracterizar a bovinocultura na região. Para o Estado de Rondônia, especificamente, não há informações sobre a organização do sistema produtivo e sobre a situação epidemiológica da brucelose.

O presente estudo teve por objetivos estimar a prevalência e identificar os fatores de risco para a brucelose bovina no Estado, e fornecer subsídios para a melhor implementação e gestão do Programa Nacional de Controle e Erradicação de Brucelose e Tuberculose (PNCEBT).

\section{MATERIAL E MÉTODOS}

O estudo foi planejado por técnicos do Ministério da Agricultura, Pecuária e Abastecimento, da Universidade de São Paulo e da Universidade de Brasília, em colaboração com os da IDARON. O trabalho de campo foi realizado por técnicos da IDARON, no período de março a setembro de 2004.

Para o conhecimento das diferenças regionais nos parâmetros epidemiológicos da brucelose bovina, o Estado de Rondônia foi dividido em três circuitos produtores de bovinos, levando-se em consideração os diferentes sistemas de produção, práticas de manejo, finalidades de exploração, tamanho médio de rebanhos e sistemas de comercialização. A divisão do Estado em regiões correspondentes a circuitos produtores também levou em conta a capacidade operacional e logística do serviço veterinário oficial do Estado para a realização das atividades de campo, baseando-se nas áreas de atuação das suas unidades regionais.

Em cada circuito produtor, estimou-se a prevalência de propriedades infectadas pela brucelose bovina e a de animais soropositivos por meio de um estudo amostral em dois estágios, dirigido para detectar focos da doença. No primeiro estágio, sorteou-se, aleatoriamente, um número pré-estabelecido de propriedades com atividade reprodutiva (unidades primárias de amostragem). No segundo, sorteou-se um número pré-estabelecido de fêmeas bovinas com idade igual ou superior a 24 meses (unidades secundárias de amostragem).

Nas propriedades rurais onde existia mais de um rebanho, foi escolhido o rebanho bovino de maior importância econômica, no qual os animais estavam submetidos ao mesmo manejo, ou seja, sob os mesmos fatores de risco. A escolha da unidade primária de amostragem foi aleatória, baseada no cadastro de propriedades rurais com atividade reprodutiva de bovinos. A propriedade sorteada que, por motivos vários, não pôde ser visitada, foi substituída por outra, nas proximidades e com as mesmas características de produção. $\mathrm{O}$ número de propriedades selecionadas por circuito foi estimado pela fórmula para amostras simples 
aleatórias (Thrusfield, 2007). Os parâmetros adotados para o cálculo foram: nível de confiança de 0,95 , prevalência estimada de 0,25 e erro de 0,05. A capacidade operacional e financeira do serviço veterinário oficial do Estado também foi levada em consideração para a determinação do tamanho da amostra por circuito.

O planejamento amostral para as unidades secundárias visou estimar um número mínimo de animais a serem examinados dentro de cada propriedade de forma a permitir a sua classificação como foco ou não foco de brucelose. Para tanto, foi utilizado o conceito de sensibilidade e especificidade agregadas (Dohoo et al., 2003). Para efeito dos cálculos foram adotados os valores de $95 \%$ e $99,5 \%$, respectivamente, para a sensibilidade e a especificidade do protocolo de testes utilizado (Fletcher et al., 1998) e 20\% para a prevalência estimada. Nesse processo foi utilizado o programa Herdacc versão 3 , e o tamanho da amostra escolhido foi aquele que permitiu valores de sensibilidade e especificidade de rebanho iguais ou superiores a 90\%. Assim, nas propriedades com até 99 fêmeas com idade superior a 24 meses, foram amostrados 10 animais e nas com 100 ou mais fêmeas com idade superior a 24 meses, 15 animais. A escolha das fêmeas dentro das propriedades foi casual sistemática.

O protocolo do sorodiagnóstico foi composto pela triagem com o teste do antígeno acidificado tamponado (Rosa Bengala), seguida do reteste dos positivos com o teste do 2-mercaptoetanol, de acordo com as recomendações do PNCEBT (Brasil, 2006). O sangue foi coletado por punção da veia jugular com agulha descartável estéril em tubo com vácuo, previamente identificado. Os soros, armazenados em microtubos de plástico, foram mantidos a $-20^{\circ} \mathrm{C}$ até a realização dos testes. Os testes sorológicos de triagem foram realizados no IDARON (SEAPES) e os testes confirmatórios (2-mercaptoetanol) no LANAGRO, Pedro Leopoldo, MG.

A propriedade foi considerada positiva quando se detectou pelo menos um animal positivo. As propriedades que apresentaram animais com resultado sorológico inconclusivo, sem nenhum positivo, foram classificadas como suspeitas e excluídas das análises. $\mathrm{O}$ mesmo tratamento foi dado aos animais com resultados sorológicos inconclusivos.

O planejamento amostral permitiu determinar as prevalências de focos e de fêmeas adultas $(\geq 24 \mathrm{~m})$ soropositivas para brucelose no Estado e também nos circuitos produtores. Os cálculos das prevalências aparentes e os respectivos intervalos de confiança foram realizados conforme preconizado por Dean et al. (1994). Os cálculos das prevalências de focos e de animais no Estado, e de prevalências de animais dentro das regiões foram feitos de forma ponderada (Dohoo et al., 2003).

O peso de cada propriedade no cálculo da prevalência de focos no Estado foi dado por

$$
P_{1}=\frac{\text { propriedad es na região }}{\text { propriedad es amostradas na região }}
$$

O peso de cada animal no cálculo da prevalência de animais no Estado foi dado por

$P_{2}=\frac{\text { fêmeas } \geq 24 \text { meses na propriedade }}{\text { fêmeas } \geq 24 \text { meses amostradas na propriedade }} \times$ $\times \frac{\text { fêmeas } \geq 24 \text { meses na região }}{\text { fêmeas } \geq 24 \text { meses nas propriedades amostradas na região }}$
$\mathrm{Na}$ expressão acima, o primeiro termo refere-se ao peso de cada animal no cálculo das prevalências de animais dentro das regiões.

Em cada propriedade amostrada, além da coleta de sangue para a sorologia, foi também aplicado um questionário epidemiológico, elaborado para obter informações sobre o tipo de exploração e as práticas de manejo empregadas.
As variáveis analisadas foram: tipo ou sistema de exploração (carne, leite e misto), tipo de criação (confinado, semiconfinado, extensivo), uso de inseminação artificial, raças predominantes, número de vacas com idade superior a 24 meses, número de bovinos na propriedade, presença de outras espécies domésticas, presença de animais silvestres, destino da placenta e dos fetos abortados, compra e venda de animais, vacinação 
contra brucelose, abate de animais na propriedade, aluguel de pastos, pastos comuns com outras propriedades, pastos alagados, piquete de parição e assistência veterinária.

As variáveis foram organizadas de modo a apresentarem-se em escala crescente de risco. Quando necessário, realizou-se a recategorização das variáveis. A categoria de menor risco foi considerada como base para a comparação das demais categorias. As variáveis quantitativas foram categorizadas em percentis.

Foi feita uma primeira análise exploratória dos dados (univariada) para seleção daquelas com $\mathrm{p} \leq 0,20$ para o teste do $\chi^{2}$ ou exato de Fisher e, subsequente, oferecimento dessas à regressão logística. Os cálculos foram realizados com o auxílio do programa SPSS, versão 9.0.

Todas as informações geradas pelo trabalho de campo e de laboratório foram inseridas em um banco de dados específico, utilizado nas análises epidemiológicas.

\section{RESULTADOS E DISCUSSÃO}

O Estado foi dividido em três circuitos, considerando as características regionais da produção pecuária (Fig. 1). Na Tab. 1, apresentam-se os dados censitários e o tamanho da amostra estudada em cada um dos circuitos produtores. Os valores da mediana para tamanho dos rebanhos em propriedades de corte, leite e mista foram de $124,58,5$ e 77 , respectivamente.

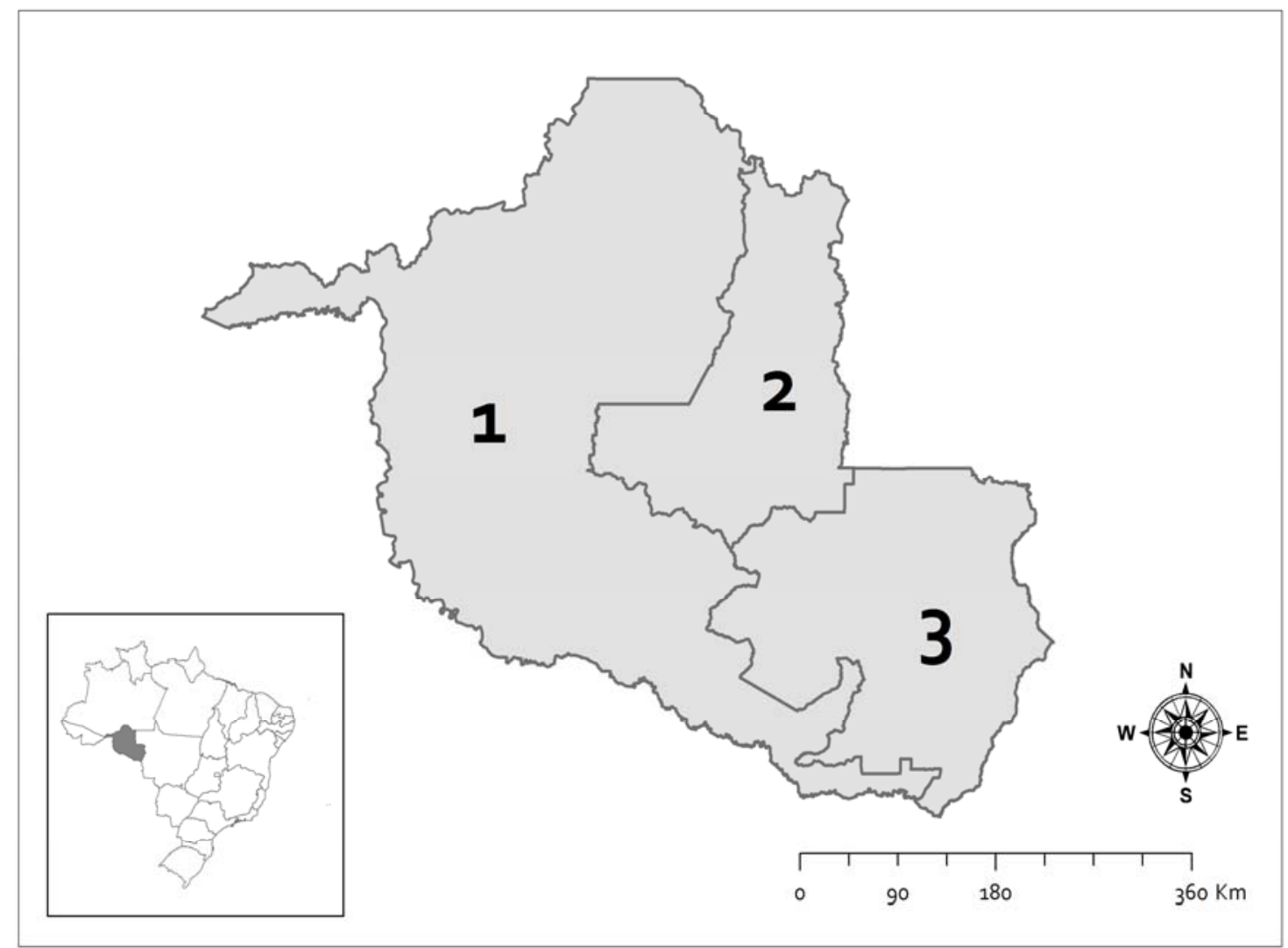

Figura 1. Mapa do Estado de Rondônia com a divisão em circuitos produtores. No detalhe, a localização da Unidade Federativa no Brasil. 
Tabela 1. Dados censitários da população bovina do Estado de Rondônia, segundo o circuito produtor

\begin{tabular}{lcccc}
\hline \multicolumn{1}{c}{ Circuito produtor } & $\begin{array}{c}\text { Total de propriedades } \\
\text { com atividade } \\
\text { reprodutiva }\end{array}$ & $\begin{array}{c}\text { Propriedades } \\
\text { amostradas }\end{array}$ & $\begin{array}{c}\text { Total de } \\
\text { fêmeas com } \\
\text { idade } \geq 24 \\
\text { meses }\end{array}$ & Fêmeas amostradas \\
\hline 1- Norte-Oeste-Sul & 13.653 & 311 & 1.162 .413 & 3.300 \\
2- Nordeste & 18.143 & 306 & 1.159 .407 & 3.150 \\
3- Sudeste & 17.852 & 310 & 1.329 .597 & 3.267 \\
Total & 49.648 & 927 & 3.651 .417 & 9.717 \\
\hline
\end{tabular}

Os circuitos 1 e 3 apresentaram três propriedades inconclusivas cada. Essas seis propriedades foram excluídas dos cálculos de prevalência.

$\mathrm{Na}$ Tab. 2, mostram-se os resultados de prevalência de focos no Estado e nos circuitos produtores. A Tab. 3 traz a prevalência de focos por tipo de exploração da propriedade e a Tab. 4, a prevalência de animais. $\mathrm{Na}$ única propriedade do circuito 1 com rebanho composto por bovinos e bubalinos, não foram detectados animais positivos.

Tabela 2. Prevalência de focos de brucelose bovina na propriedade, segundo o circuito produtor, no Estado de Rondônia, 2007

\begin{tabular}{|c|c|c|c|c|}
\hline \multirow{2}{*}{$\begin{array}{l}\text { Circuito } \\
\text { produtor }\end{array}$} & \multicolumn{2}{|c|}{ Propriedades } & \multirow{2}{*}{ Prevalência (\%) } & \multirow{2}{*}{ IC (95\%) } \\
\hline & Testadas & Positivas & & \\
\hline 1- Norte-Oeste-Sul & 308 & 129 & 41,88 & {$[36,31-47,61]$} \\
\hline 2- Nordeste & 306 & 97 & 31,70 & {$[26,52-37,24]$} \\
\hline 3- Sudeste & 307 & 98 & 31,92 & {$[26,74-37,45]$} \\
\hline Total & 921 & 324 & 35,18 & {$[32,09-38,36]$} \\
\hline
\end{tabular}

IC: intervalo de confiança.

Tabela 3. Prevalência de focos de brucelose bovina estratificada por tipo de exploração, segundo o circuito produtor, no Estado de Rondônia

\begin{tabular}{|c|c|c|c|c|c|c|}
\hline \multirow{2}{*}{$\begin{array}{l}\text { Circuito } \\
\text { produtor }\end{array}$} & \multicolumn{2}{|c|}{ Corte } & \multicolumn{2}{|c|}{ Leite } & \multicolumn{2}{|c|}{ Misto } \\
\hline & Prev (\%) & IC (95\%) & Prev (\%) & $\overline{\mathrm{IC}(95 \%)}$ & Prev (\%) & IC $(95 \%)$ \\
\hline 1- Norte-Oeste-Sul & 57,47 & {$[46,41-68,01]$} & 32,69 & {$[23,81-42,59]$} & 38,46 & {$[29,62-47,90]$} \\
\hline 2- Nordeste & 35,00 & {$[20,63-51,68]$} & 30,38 & {$[23,32-38,19]$} & 32,41 & {$[23,72-42,09]$} \\
\hline 3-Sudeste & 38,74 & {$[29,64-48,45]$} & 28,87 & {$[20,11-38,95]$} & 27,27 & {$[18,80-37,15]$} \\
\hline
\end{tabular}

IC: intervalo de confiança.

Tabela 4. Prevalência de animais sororreagentes para brucelose, segundo o circuito produtor, no Estado de Rondônia, 2007

\begin{tabular}{|c|c|c|c|c|}
\hline \multirow{2}{*}{ Circuito produtor } & \multicolumn{2}{|c|}{ Animais } & \multirow{2}{*}{ Prevalência (\%) } & \multirow{2}{*}{ IC $(95 \%)$} \\
\hline & Testados & Positivos & & \\
\hline 1- Norte-Oeste-Sul & 3.293 & 216 & 8,33 & {$[5,90-10,75]$} \\
\hline 2- Nordeste & 3.149 & 171 & 5,99 & {$[4,33-7,66]$} \\
\hline 3-Sudeste & 3.261 & 173 & 4,58 & {$[2,52-6,64]$} \\
\hline Total & 9.703 & 560 & 6,22 & {$[4,88-7,56]$} \\
\hline
\end{tabular}

IC: intervalo de confiança. 
Na Tab. 5, mostram-se os resultados da análise univariada e na Tab. 6, o modelo final da regressão logística.

A prevalência de focos de brucelose para o Estado de Rondônia foi de 35,2\% [32,1-38,4\%] (Tab. 2) e a prevalência de animais soropositivos no Estado de 6,2\% [4,9-7,6\%] (Tab. 4). O circuito produtor 1 apresentou a maior prevalência de focos, 41,9\% [36,3-47,6\%]. Não houve diferença significativa na prevalência entre os circuitos produtores 2 e 3 (Tab. 2).

A prevalência de focos de brucelose no Estado, estratificada por tipo de exploração, não apresentou diferença significativa entre circuitos, muito embora tenha havido tendência para valores mais elevados em propriedades de corte. Não houve diferença na prevalência de animais positivos entre circuitos. Em resumo, esses dados mostram que o Estado de Rondônia caracterizase por alta prevalência e homogeneidade na frequência de focos e de animais nos circuitos 2 e 3. Verificou-se forte tendência de maior concentração da doença no circuito produtor 1 . Nos três circuitos, observou-se tendência de concentração da doença em propriedades de gado de corte. A diminuição da prevalência com baixo custo pode ser alcançada por eficiente programa de vacinação de fêmeas. Os dados apresentados neste estudo constituem o primeiro levantamento de prevalência da brucelose para o Estado de Rondônia segundo o circuito produtor.

Tabela 5. Resultados da análise univariada dos possíveis fatores de risco para brucelose bovina em rebanhos com atividade reprodutiva no Estado de Rondônia, 2007

\begin{tabular}{|c|c|c|c|}
\hline Variável & Expostos/Casos & Expostos /Controles & $\mathrm{p}$ \\
\hline Sistema de criação extensiva & $16 / 324$ & $22 / 597$ & 0,361 \\
\hline Exploração de corte ${ }^{\mathrm{a}, \mathrm{b}}$ & $217 / 324$ & $466 / 597$ & $<0,001$ \\
\hline Contato com ovinos ${ }^{\mathrm{a}, \mathrm{b}}$ & $276 / 324$ & $529 / 597$ & 0,135 \\
\hline Contato com equinos & $28 / 324$ & $45 / 597$ & 0,554 \\
\hline Contato com suínos $^{\mathrm{a}}$ & $181 / 324$ & $268 / 597$ & 0,001 \\
\hline Contato com aves ${ }^{\mathrm{a}}$ & $56 / 324$ & $60 / 597$ & 0,002 \\
\hline Contato com cão $^{\mathrm{a}}$ & $68 / 324$ & $87 / 597$ & 0,013 \\
\hline Contato com gato $^{\mathrm{a}}$ & $120 / 324$ & $191 / 597$ & 0,122 \\
\hline Contato com animais silvestres & $182 / 324$ & $349 / 597$ & 0,503 \\
\hline Contato com cervídeos & $272 / 324$ & $502 / 597$ & 0,957 \\
\hline Contato com capivaras & $241 / 324$ & $451 / 597$ & 0,697 \\
\hline Contato com outros animais silvestres ${ }^{\mathrm{a}}$ & $218 / 324$ & $426 / 597$ & 0,198 \\
\hline Utiliza a inseminação artificial & $6 / 324$ & $16 / 597$ & 0,432 \\
\hline Compra de animais para reprodução & $128 / 324$ & $255 / 596$ & 0,335 \\
\hline Teste para brucelose $\mathrm{e}^{\mathrm{a}, \mathrm{b}}$ & $245 / 324$ & $479 / 596$ & 0,093 \\
\hline Histórico de aborto ${ }^{\mathrm{a}, \mathrm{b}}$ & $233 / 324$ & $467 / 596$ & 0,029 \\
\hline Deixa produtos do aborto na pastagem & $125 / 324$ & $211 / 595$ & 0,348 \\
\hline Aluga pasto & $239 / 322$ & $437 / 596$ & 0,767 \\
\hline Pasto comum com outras propriedades & $251 / 324$ & $455 / 596$ & 0,699 \\
\hline Presença de áreas alagadiças & $173 / 323$ & $322 / 596$ & 0,892 \\
\hline Presença de piquetes de parição & $183 / 324$ & $355 / 596$ & 0,365 \\
\hline Vacina contra brucelose $\mathrm{e}^{\mathrm{a}, \mathrm{b}}$ & $136 / 324$ & $205 / 597$ & 0,022 \\
\hline Ausência de assistência veterinária & $299 / 324$ & $560 / 597$ & 0,380 \\
\hline
\end{tabular}

${ }^{\mathrm{a}} \mathrm{p}<0,20$ na análise univariada.

${ }^{\mathrm{b}}$ Variáveis oferecidas à análise de regressão logística multivariada. 
Tabela 6. Modelo final da regressão logística multivariada de fatores de risco (odds ratio) para brucelose bovina em rebanhos com atividade reprodutiva no Estado de Rondônia, 2007

\begin{tabular}{lccc}
\multicolumn{1}{c}{ Variável } & Odds ratio & IC (95\%) & p \\
\hline Histórico de aborto & 1,421 & {$[1,039-1,944]$} & $<0,001$ \\
Exploração de corte & 1,755 & {$[1,297-2,376]$} & $<0,001$ \\
\hline
\end{tabular}

IC: intervalo de confiança.

O modelo final da regressão logística indicou que as variáveis histórico de aborto e exploração de corte estão associadas à condição de foco de brucelose no Estado (Tab. 6).

O histórico de aborto é uma consequência da infecção brucélica, pois o abortamento é o principal sinal da doença na espécie bovina (Acha e Szyfres, 2001).

Propriedades de corte contavam com número maior de animais - mediana de 124 , contra 58,5 e 77 para propriedade de leite e exploração mista, respectivamente. Nos grandes rebanhos não há diferenças individuais quanto à suscetibilidade à doença, mas algumas características desses grandes rebanhos podem facilitar a transmissão da brucelose, tais como: maior frequência de reposição de animais, maior quantidade de problemas relacionados ao controle sanitário e a influência na dinâmica da doença (Crawford et al., 1990). Christie (1969) observou que o aumento do rebanho resulta em aumento da probabilidade de ocorrer a doença e de persistir a infecção, e aumento da prevalência da doença e da dificuldade de erradicá-la. Assim, número elevado de animais no rebanho significa maior risco de introdução e disseminação da brucelose. Esses dados confirmam os resultados obtidos no estudo de prevalência em que foi verificada uma tendência de maior concentração da infecção nos estratos de propriedades de gado de corte. Assim, a característica relevante seria o tamanho do rebanho e não o tipo de exploração, uma vez que sua associação com a presença de brucelose foi demonstrada em vários estudos (Kellar et al., 1976; Nicoletti 1980; Salman e Meyer, 1984).

Esses resultados sugerem que $\mathrm{o}$ fator mais importante para a disseminação da brucelose no Estado é a introdução de animais sem cuidados sanitários, que emergiu de forma indireta, pela interpretação da variável rebanho de corte.
Recomenda-se: concentrar esforços para vacinar, todos os anos, um mínino de $80 \%$ das bezerras entre três e oito meses de idade com a amostra B19 e desencorajar a introdução de animais sem controle sanitário.

\section{AGRADECIMENTOS}

À FAPESP, ao CNPq, à SEAB-RO, ao IDARON- RO e ao MAPA pelo apoio financeiro.

\section{REFERÊNCIAS BIBLIOGRÁFICAS}

ACHA, P.N.; SZYFRES, B. Zoonosis y enfermedades transmisibles comunes al hombre y a los animales: Bacterioses e micoses. 3.ed. Washington: OPAS, 2001. 416p.

BRASIL. Ministério de Agricultura, Pecuária e Abastecimento. Programa Nacional de Controle e Erradicação da Brucelose e da Tuberculose Animal (PNCEBT): Manual técnico. Brasília, 2006. 184p.

CHRISTIE, T.E. Eradication of brucellosis in Northern Ireland: Field problems and experiences. Vet. Rec., v.85, p.268-269, 1969.

CRAWFORD, R.P.; HUBER, J.D.; ADAMS, B.S. Epidemiology and surveillance. In: NIELSEN, K.; DUNCAN, J.R. (Ed.). Animal brucellosis. Boca Raton: CRC Press, 1990. p.131-151.

DEAN, A.G.; DEAN, J.A.; COLOMBIER, D. et al. Epi-Info, version 6: A word processing database and statistics program for epidemiology on microcomputers. Atlanta: CDC, 1994. 601p.

DOHOO, I.; MARTIN, W.; STRYHN, H. Veterinary epidemiologic research. Charlottetown, Canadá: Atlantic Veterinary College, 2003. 706p.

FLETCHER, R.H.; FLETCHER, S.W.; WAGNER, E.H. Clinical epidemiology: The 
essentials. 2.ed. Baltimore: Williams \& Wilkins, 1998. 246p.

IBGE. Rio de Janeiro, 2005. Disponível em: $<$ http:www.sidra.ibge.gov.br $>$. Acessado em: 7 mai. 2007.

KELLAR， J.; MARRA， R.; MARTIN, W. Brucellosis in Ontario: a case control study. Can J. Comp. Med., v. 40, p.119-128, 1976.

NICOLETTI, P. The epidemiology of bovine brucellosis. Adv. Vet. Sci. Comp. Med., v.24, p.69-98, 1980.
SALMAN, M.D.; MEYER, M.E. Epidemiology of bovine brucellosis in the Mexicali Valley, México: Literature review of disease-associated factors. Am. J. Vet. Res., v.45, p.1557-1560, 1984.

THRUSFIELD, M. Veterinary epidemiology. 3.ed. Oxford: Blackwell Science, 2007. 610p. 